\title{
IMPLEMENTASI PERATURAN DAERAH NOMOR 09 TAHUN 2014 TENTANG PENGELOLAAN PASAR RAKYAT, PUSAT PERBELANJAAN DAN TOKO SWALAYAN DI KOTA PEKANBARU
}

\author{
Azwita \\ Universitas Lancang Kuning, Indonesia, witalaw20@gmail.com \\ Ali Ismail Shaleh \\ Universitas Muhammadiyah Riau, Indonesia, aliismailshaleh@gmail.com
}

\begin{abstract}
The purpose of the study was to obtain a portrait of the partnership between Supermarkets (minimarkets) and MSMEs in the Pekanbaru City area and to find out the obstacles and solutions in the application of Regional Regulation Number 09 of 2014 concerning Management of People's Markets, Shopping Centers and Supermarkets in Pekanbaru City. Methods This research is a Socio Legal research with the category of legal effectiveness. Legal effectiveness research discusses the law operating in society, so that it can reveal the effectiveness of the law in the community itself. The results of the study show that the application of regional regulations to business actors in modern shops and SMEs has not been running properly and effectively as it should. This means that the partnership between Supermarkets and MSMEs has not been carried out in accordance with Regional Regulations and needs to be disseminated to business actors. From the existing regulations, there are no implementing regulations for Perda or Perwako that contain detailed and measurable forms of partnership. Barriers to the application of this regional regulation are the lack of facilities and infrastructure as well as the low legal awareness for minimarket business actors against the regional regulation as well as the lack of human resources (HR) and the lack of innovation in the products they sell because there are still MSMEs that have not taken care of licensing in accordance with the regulations. local regulations.
\end{abstract}

Keywords: Regional Regulation, UMKM, Partnership.

\begin{abstract}
Abstrak
Tujuan Penelitian adalah untuk mendapatkan potret kemitraan antara Toko Swalayan (minimarket) dengan UMKM di wilayah Kota Pekanbaru dan untuk mengetahui hambatan dan Solusi dalam Penerapan Peraturan Daerah Nomor 09 Tahun 2014 tentang Pengelolaan Pasar Rakyat, Pusat Perbelanjaan dan Toko Swalayan di Kota Pekanbaru. Metode Penelitian ini adalah penelitian Socio Legal Research dengan kategori efektivitas hukum. Penelitian efektivitas hukum membahas tentang hukum beroperasi di masyarakat, sehingga dapat mengungkapkan efektivitas berlakunya hukum di masyarakat itu sendiri. Hasil dari penelitian diketahui bahwa Penerapan Peraturan Daerah terhadap pelaku usaha Toko Modren dan UMKM belum berjalan dengan baik dan efektif sebagaimana mestinya. Artinya kemitraan antara Toko Swalayan dengan UMKM belum berjalan sesuai dengan Peraturan Daerah dan perlu mensosialisasikan kepada para pelaku usaha. Dari peraturan yang telah ada belum ada peraturan pelaksanaan Perda atau Perwako yang memuat bentuk kemitraan secara rinci dan terukur. Hambatan
\end{abstract}


dalam Penerapan Peraturan Daerah ini masih kurangnya sarana dan prasarana serta masih rendahnya kesadaran hukum bagi pelaku usaha minimarket terhadap Peraturan Daerah tersebut serta kurangnya Sumber Daya Manusia (SDM) serta kurangnya inovasi terhadap prodak yang meraka jual dikarenakan masih adanya UMKM yang belum mengurus perizinan sesuai dengan aturan Peraturan Daerah.

Kata Kunci: Peraturan Daerah, UMKM, Kemitraan.

\section{Pendahuluan}

Usaha Mikro, Kecil dan Menengah (yang selanjutnya di singkat dengan UMKM) menjadi salah satu dari tulang punggung perekonomian Indonesia. Karena dengan UMKM ini, ${ }^{1}$ pengangguran akibat angkatan kerja yang tidak terserap dalam dunia kerja menjadi berkurang. Sektor UMKM telah dipromosikan dan dijadikan sebagai agenda utama pembangunan ekonomi Indonesia, untuk itu perlu diadakan upaya-upaya untuk meningkatkan UMKM yang ada di Indonesia dengan cara mengoptimalkan potensi-potensi ekonomi. ${ }^{2}$

\footnotetext{
${ }^{1}$ David A. Masta, Competition and Product Quality In The Supermarket Industry, The Quarterly Journal Of Economics, Volume 126, Issues 3, Agust 2011, Pages 1539-1591.

Tambunan, T. (2014), UMKM INDONESIA, Usaki, Hal. 359.
}

Dari sekian banyak usaha ritel modern yang berkembang di Indonesia yang paling banyak dijumpai adalah Indomaret dan Alfamart. Indomaret sendiri dikelola oleh PT. Indomarco Prismatama (Indofood Group) sedangkan Alfamart dikelola oleh dua perusahaan yakni Alfa Group dan PT HM Sampoerna,Tbk. Kedua pelaku usaha tersebut terus bersaing untuk mendapatkan laba, tidak hanya satu gerai yang ada pada setiap kota namun terdapat puluhan gerai yang berdiri untuk menarik minat serta memenuhi kebutuhan masyarakat, ini adalah salah satu usaha minimarket yang berkembang saat ini, masih banyak lagi minimarket yang tersebar disetiap sudut kota Pekanbaru yang menawarkan dengan system syariah seperti Mini Mart 212, Tull Mart, Mulia Mart dan lain sebagainya. 
Berdasarkan Rekapitulasi Rekomendasi Izin

Usaha Toko Modren, Indomaret berjumlah

261 gerai, Alfamart 149 gerai, umum 65 gerai dengan total keseluruhan berjumlah 475 gerai tersebar di Kota Pekanbaru. ${ }^{3}$

Peraturan Presiden Nomor 112 Tahun 2007 menerangkan bahwa pasar adalah area tempat jual beli barang atau tempat bertemunya pedagang dan pembeli. Adapun pengertian pasar berdasarkan jenisnya:

1. Pasar Tradisional adalah pasar dengan ciri utama tawar menawar harga dalam proses jual beli.

2. Pasar modren merupakan area jual beli yang memiliki harga yang pasti.

3. Toko modern adalah toko dengan sistem pelayanan mandiri yang menjual berbagai jenis barang secara eceran. Toko Modern dibedakan menjadi:

3 Damayanti,, E., (2019) Tinjauan Hukum Islam Terhadap Eksistensi Minimarket Alfamart dan Indomaret di Indonesia, Jurnal Hukum Bisnis Islam, Vol.11, No.02 Pp. 23-25. a. Minimarket;

b. Supermarket;

c. Hypermarket;

d. Department store dan Perkulakan. $^{4}$

Perbedaan toko modern tersebut didasarkan atas luas lantai dan variasi barang dagangan. Minimarket, supermarket dan hypermarket menjual barang konsumsi terutama produk makanan dan produk rumah tangga lainnya secara eceran.

Untuk konteks daerah Pekanbaru realisasi kemitraan usaha antara pelaku usaha UMKM dengan sejumlah toko swalayan modren di wilayah Kota Pekanbaru ternyata hingga kini masih belum terwujud, meski Peraturan Daerah (Perda) Kota Pekanbaru Nomor 09 Tahun 2014 tentang Pengelolaan Pasar Rakyat, Pusat Perbelanjaan dan Toko Swalayan di Kota Pekanbaru menyebutkan bahwa setiap

4 Lihat Peraturan Presiden Nomor 112 Tahun 2007. Dalam peraturan tersebut mengatur akan eksistensi UMKM dalam pelayanan berkelanjutan dalam masyarakat. 
toko swalayan di Kota Pekanbaru berkewajiban menjalin kemitraan dengan pelaku UMKM yang ada disekitarnya. ${ }^{5}$

Ketidakefektifan permasalahan terhadap UMKM merupakan masalah kesenjangan antara das sollen dengan das sein sehingga layak untuk diteliti secara empiris atau yang dikenal dengan penelitian hukum sosiologis. ${ }^{6}$ Agar relevan dengan isu hukumnya maka penulis menetapkan judul "Penerapan Peraturan Daerah Nomor 09 Tahun 2014 tentang Pengelolaan Pasar Rakyat, Pusat Perbelanjaan dan Toko Swalayan di Kota Pekanbaru."

\section{Rumusan Masalah}

Dari uraian latar belakang di atas maka penulis menetapkan masalah pokok

\footnotetext{
${ }^{5}$ Berdasarkan Perda Kota Pekanbaru Nomor 9 Tahun 2014 tentang Pengelolaan Pasar Rakyat, Pasar Perbelanjaan dan Toko Swalayan. Konteks Perda tersebut masih belum di terapkan oleh geraigerai terdekat dalam pengoptimalan dan keberlangsungan UMKM.

${ }^{6}$ Penulisan ini beranjak dari pengembangan pemikiran dari Skripsi pada Fakultas Hukum Universitas Lancang Kuning Pekanbaru lalu di komplekskan dalam bentuk jurnal terbarukan pada Jurnal Equitable Fakultas Hukum Universitas Muhammadiyah dewasa ini.
}

dalam penulisan proposal ini adalah sebagai berikut:

1) Bagaimanakah Implementasi Peraturan Daerah Nomor 09 Tahun 2014 tentang Pengelolaan Pasar Rakyat, Pusat Perbelanjaan dan Toko Swalayan di Kota Pekanbaru?

2) Apakah Hambatan dalam Imolementasi Peraturan Daerah Nomor 09 Tahun 2014 tentang Pengelolaan Pasar Rakyat, Pusat Perbelanjaan dan Toko Swalayan di Kota Pekanbaru?

\section{Metode Penelitian}

Jenis penelitian yang digunakan adalah peninjauan langsung ke lapangan yang digolongkan pada penelitian kualitatif dengan pendekatan penelitian yang digunakan adalah Socio Legal. ${ }^{7}$ Penelitian Socio Legal adalah penelitian yang menggabungkan antara sumber normatif dan

\footnotetext{
${ }^{7}$ Shaleh, A.I., (2021) Efektivitas Formulir A 5 Pada Pemilih Pemula Pemilihan Umum Tahun 2019 di Kota Semarang, Jurnal Meta-Yuridis, Vol. 04., No. 01., P. 06.
} 


\begin{abstract}
sosiologis dalam sebuah kerangka penelitian, dengan menggunakan Sumber objek penelitian ini adalah pelaku usaha toko minimarket serta langsung kepada pelaku usaha UMKM orang yang bersangkutan dalam studi kasus penellitian ini, lalu sample dan populasi yang di rangkum sebagai berikut :
\end{abstract}

\begin{tabular}{|c|c|c|c|c|}
\hline \multirow[t]{2}{*}{ NO } & JENIS POPULASI & JUMLAH & JUMLAH & PERSENTASE \\
\hline & & POPULASI & SAMPEL & $\%$ \\
\hline \multirow[t]{5}{*}{1} & Kepala & 1 & 1 & 100 \\
\hline & Dinas & & & \\
\hline & Perindustrian & & & \\
\hline & dan & & & \\
\hline & Perdagangan & & & \\
\hline \multirow[t]{6}{*}{2} & Kota & 1 & 1 & 100 \\
\hline & Pekanbaru & & & \\
\hline & Kepala & & & \\
\hline & Dinas & & & \\
\hline & Kesehatan & & & \\
\hline & Kota & & & \\
\hline \multirow{3}{*}{3} & Pekanbaru & & & \\
\hline & Kepala & 1 & 1 & 100 \\
\hline & Dinas & & & \\
\hline
\end{tabular}

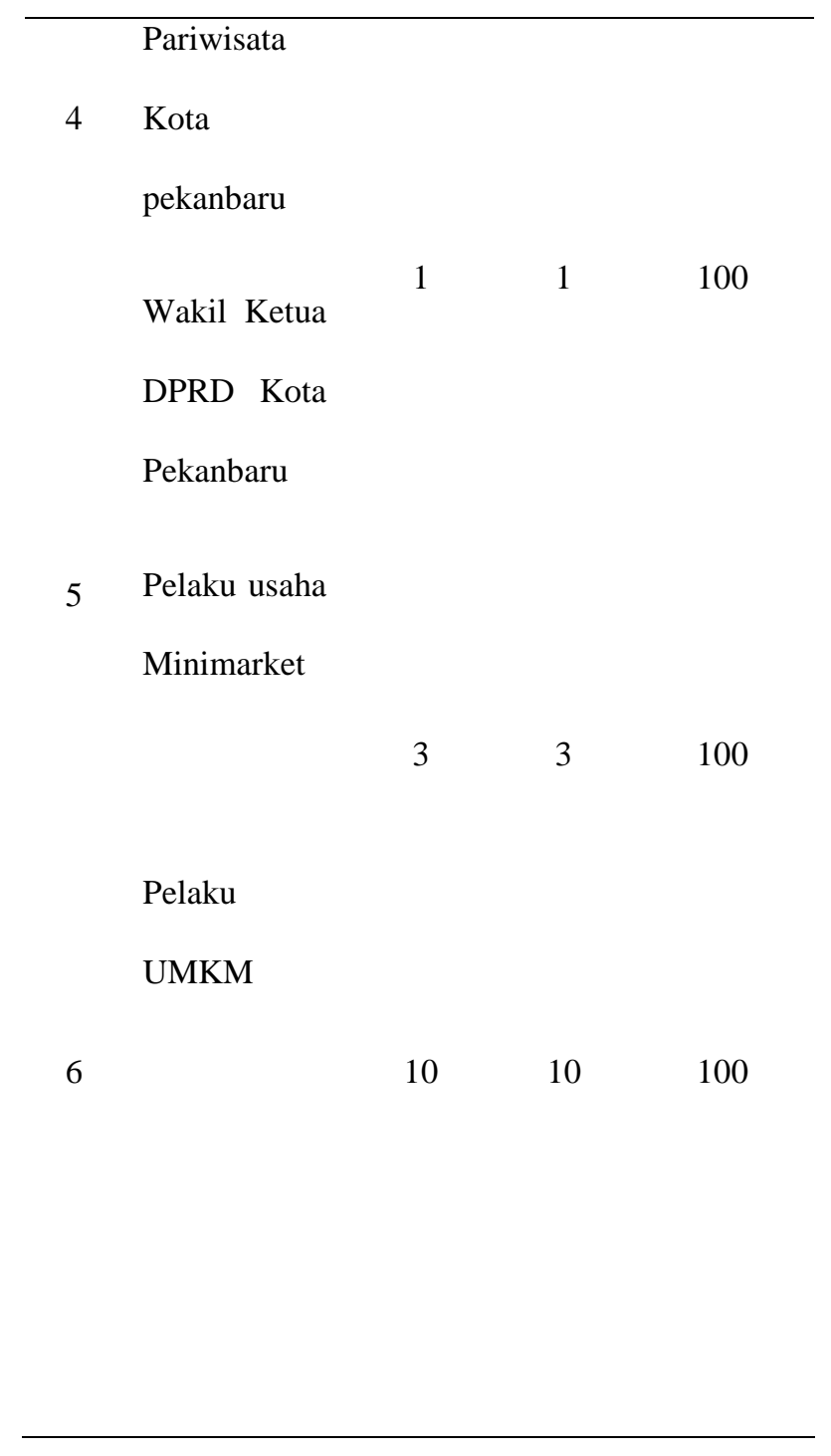

\section{Hasil Penelitian dan Pembahasan}

\section{Implementasi Peraturan Daerah}

Nomor 09 Tahun 2014 Pasar Rakyat, Pusat Perbelanjaan dan Toko Swalayan di Kota Pekanbaru

Perkembangan Kota Pekanbaru sebagai tempat tujuan investasi di Indonesia khususnya di pulau Sumatera 
yang semakin hari semakin mengalami peningkatan berdampak pada tumbuhnya secara subur berbagai sarana perdagangan yang didukung dengan kepemilikan modal yang besar seperti Toko Swalayan, Pusat Perbelanjaan, Perkulakan yang bersifat grosir termasuk juga rantai distribusi yang bersifat umum terutama waralaba telah membuat entitas Pasar Rakyat yang merupakan urat nadi perekonomian masyarakat menengah kebawah menjadi semakin tersaingi dan bahkan terdistorsi. $^{8}$

Jika melihat secara detail mengenai Kota Pekanbaru yang semakin pesat maka dapat di lihat dari jumlah penduduknya;

\begin{tabular}{ccccc}
\hline N & Kecamata & Laki- & Pere & Jumla \\
o & n & laki & mpu & h \\
& & & & \\
& & & &
\end{tabular}

8 Manalo, H. (2011) Selamatkan Pasar Tradisonal, Gramedia Pustaka Utama, hlm. 13.

\begin{tabular}{|c|c|c|c|c|}
\hline \multirow[t]{2}{*}{1} & Sukajadi & 26.10 & 27.6 & \multirow[t]{2}{*}{47.363} \\
\hline & & 8 & 69 & \\
\hline \multirow[t]{2}{*}{2} & Pekanbaru & 15.66 & 15.3 & \multirow[t]{2}{*}{25.094} \\
\hline & Kota & 7 & 49 & \\
\hline \multirow[t]{2}{*}{3} & Sail & 11.50 & 11.5 & \multirow[t]{2}{*}{21.479} \\
\hline & & 5 & 66 & \\
\hline \multirow[t]{2}{*}{4} & Lima & 21.79 & 22.3 & \multirow[t]{2}{*}{41.437} \\
\hline & Puluh & 5 & 78 & \\
\hline \multirow[t]{2}{*}{5} & Senapelan & 19.18 & 19.0 & \multirow[t]{2}{*}{36.548} \\
\hline & & 7 & 59 & \\
\hline \multirow[t]{2}{*}{6} & Rumbai & 24.92 & 23.3 & \multirow[t]{2}{*}{67.523} \\
\hline & & 1 & 85 & \\
\hline \multirow[t]{2}{*}{7} & Bukit & 40.70 & 39.6 & 103.11 \\
\hline & Raya & 5 & 96 & 4 \\
\hline \multirow[t]{2}{*}{8} & Tampan & 48.69 & 44.7 & 269.06 \\
\hline & & 8 & 11 & 2 \\
\hline \multirow[t]{2}{*}{9} & Marpoyan & 62.00 & 54.5 & 131.24 \\
\hline & Damai & 7 & 56 & 5 \\
\hline 10 & Tenayan & 45.23 & 48.0 & 158.51 \\
\hline
\end{tabular}




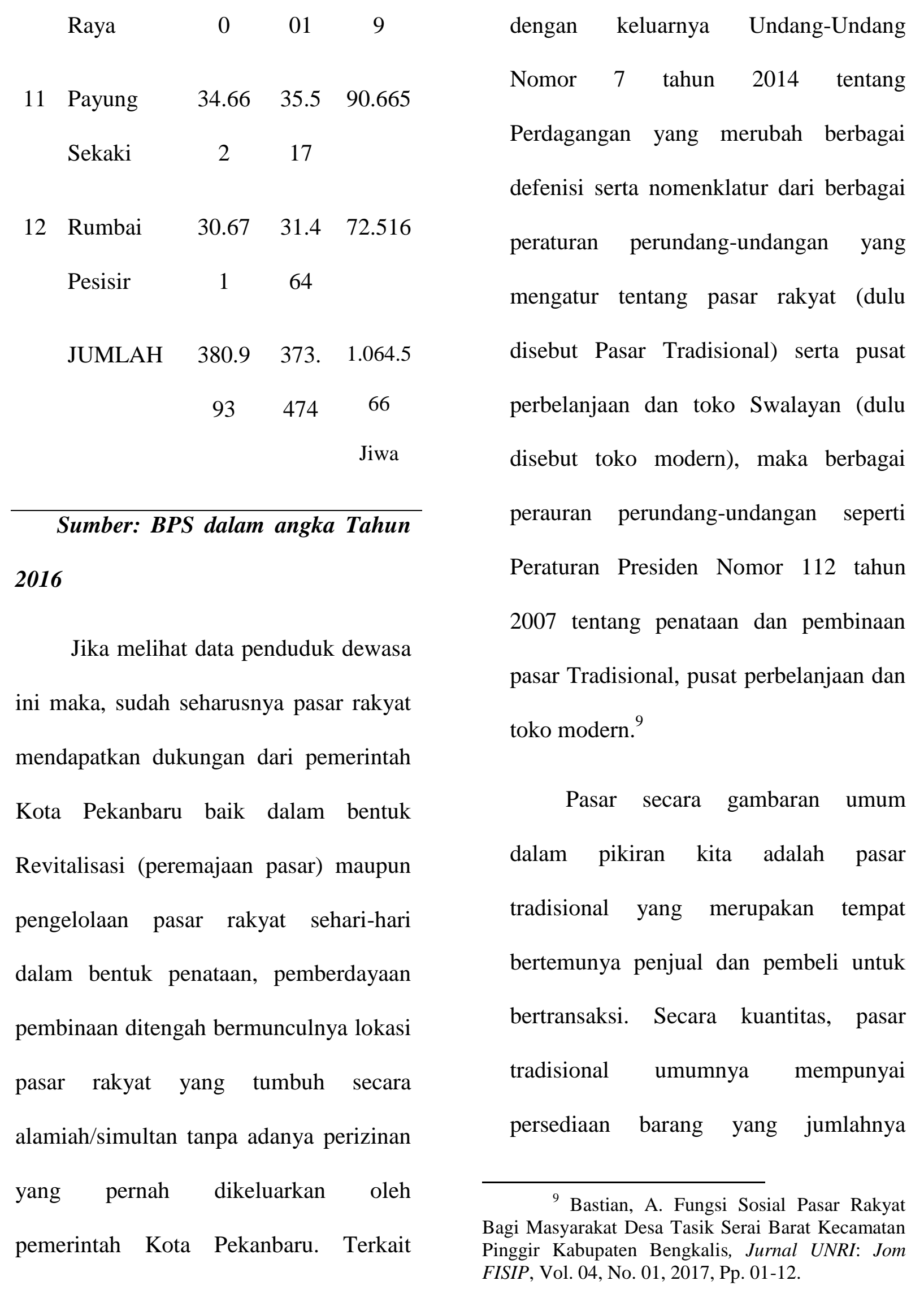


sedikit sesuai dengan modal yang dimiliki pemilik atau permintaan dari konsumen. Dari segi harga, pasar tradisional tidak memiliki label harga yang pasti karena harga disesuaikan dengan besarnya keuntungan yang diinginkan oleh setiap pemilik usaha sendiri-sendiri.

Berikut adalah jenis usaha dan pasar sesuai data yang di dapatkan sebagai berikut:

\begin{tabular}{lccc}
\hline No & Jenis & Tahun & Tahun \\
& Usaha & 2018 & 2019 \\
1 & Mikro & 10.770 & 11.183 \\
2 & Kecil & 2.704 & 2.774 \\
3 & Menengah & 149 & 163 \\
& & & \\
& Jumlah & 13.623 & 14.120 \\
\hline
\end{tabular}

Sumber Data : Dinas Koperasi dan UMKM 2019

Selain itu, harga pasar selalu berubah-ubah, Pasar demikian diartikan secara sempit atau tempat dimana pada umumnya barang atau jasa diperjualbelikan. Akan tetapi pasar tidak sebatas itu. Adapula pasar yang tidak mempertemukan pembeli dan penjual secara langsung, seperti pasar saham. Pasar juga dapat diartikan secara luas, sebagai proses dimana pembeli dan penjual saling berinteraksi untuk menentukan atau menetapkan harga yang telah disepakati.

Dengan demikian pasar adalah keseluruhan permintaan dan penawaran barang, jasa atau factor produksi tertentu. Selanjutnya, kehadiran pasar modern terutama supermarket dan hypermart dianggap oleh berbagai kalangan telah menyudutkan keberadaan pasar tradisional. Pasar modern tidak banyak berbeda dari pasar tradisional, dikelola dengan manajemen modern, umumnya terdapat di kawasan perkotaan, sebagai penyedia barang dan jasa dengan mutu 
dan pelayanan yang baik kepada

konsumen Pasar jenis ini penjual dan

pembelinya tidak bertransaksi secara

langsung melainkan pembeli melihat

label harga yang tercantum dalam barang

(barcode). ${ }^{10}$

Berikut adalah data yang di dapatkan dari pelaku UMKM di PEMKO

Pekanbaru Tahun 2019.

\begin{tabular}{|c|c|c|c|}
\hline \multirow[t]{2}{*}{ No } & Jenis & Tahun & Tahun \\
\hline & Usaha & 2018 & 2019 \\
\hline 1 & Kuliner & 4.173 & 4.395 \\
\hline 2 & Fashion & 334 & 380 \\
\hline 3 & Pendidikan & 6 & 9 \\
\hline 4 & Otomotif & 416 & 423 \\
\hline 5 & Agrobisnis & 80 & 87 \\
\hline 6 & Tehnologi & 60 & 72 \\
\hline & Internet & & \\
\hline
\end{tabular}

10 Amrizal Harahap, kondisi Pasar Tradisional di Tengah Himpitan Pasar Modren, (Medan: Jasa Press,2010) hlm.21
$6 \quad$ Lainnya $\quad 8.549 \quad 8.752$

Sumber Data : Dinas Koperasi

dan UMKM 2019

\section{Hambatan Dalam Implementasi}

Peraturan Daerah Nomor 09 Tahun

2014 tentang Pengelolaan Pasar

Rakyat, Pusat Perbelanjaan dan Toko

Swalayan di Kota Pekanbaru

Tugas untuk membenahi sistem hukum yang sudah sedemikian rupa kebablasan dan tenggelam dalam arus vested interest, adalah suatu keharusan yang tidak terelakkan dan merupakan suatu tugas berat bagi generasi mendatang, khususnya para mahasiswa hukum, intelektual hukum, maupun praktisi hukum, serta aparatur hukum. Selanjutnya pada tahapan berikutnya adalah melakukan pembenahan sumber daya manusia (SDM) yang profesional dalam bidang hukum dan berorientasi masa depan. Cara yang paling efektif adalah membenahi program kerja dan 
kinerja, mengakomodasikan tenaga profesional yang mengusai persis bidangnya dan mempunyai integritas dan reputasi serta berdedikasi tinggi dalam rangka pelatihan dan pendidikan melalui program pengembangan yang bersifat meritokrasi dan diterapkan secara komprehensif. ${ }^{11}$

Idealisme ini bukan semata-mata untuk mencari format hukum yang ideal, melainkan paling tidak mendekati hasil yang optimal untuk membenahi sistem dan mekanisme hukum yang formalistis individual tersebut agar keluar dari kebiasaannya yang hanya berorientasi kepada apa yang disebut model respresif ketimbang responsif. Hukum yang kaku menyulitkan akseptabilitas masyarakat heterogen seperti Indonesia ini. Hukum yang tidak fleksibel pada gilirannya hanya menimbulkan kompleksitas dan

\footnotetext{
11 Soerjono Soekanto, Teori Sosiologi Tentang Struktur Masyarakat, (Jakarta: Rajawali,1986), hlm. 37.
}

aneka konflik dalam kehidupan sosial, sehingga diperlukan konsepsi hukum yang akseptabel sesuai dengan pola kehidupan bermasyarakat, dan dapat diterima secara sukarela tanpa perlu dipaksakan oleh kekuasaan secara represi. $^{12}$

Berdasarkan hasil wawancara dengan Kepala Dinas Kesehatan Kota Pekanbaru mengenai Pelaksanaan Peraturan Daerah (Perda) Nomor 09 Tahun 2014 tentang Pengelolaan Pasar Rakyat, Pusat Perbelanjaan dan Toko Swalayan di Kota Pekanbaru bahwa kita ketahui Pekanbaru adalah salah satu kota yang bergerak dibidang Jasa dan Investasi. Pertumbuhan UMKM di Kota Pekanbaru sangat berkembang dengan pesat. Diharapkan UMKM itu mempunyai regulasi perizinan sesuai izin prodak yang berlaku sesuai dengan

12 H. F. Abraham Amos, Sistem Ketatanegaraan Indonesia, (Jakarta: Raja Grafindo Persada, 2005), hlm. 396. 
regulasi dari pusat maupun daerah dan diharapkan UMKM bisa berdiri sendiri terhadap prodak sendiri. Dinas Kesehatan berkerjasama dengan BPOM dan juga MUI Kota Pekanbaru untuk melakukan penyuluhan mengenai izin PIRT nya, dimana pada pelatihan tersebut juga diajarkan bagaimana makanan itu layak dan hyginies, bersih, kemudian diajarkan juga cara paking agar kemasan tersebut lebih menarik dan terjaga kwalitas prodaknya, serta di acarkan bagaimana makanan tersebut mendapatkan lebel Halal agar masyarakat lebih percaya untuk membeli produk makanan yang mereka beli dan bisa dijual di Toko Swalayan dan bukan saja dijual di pasar tradisional. . Berkaitan dengan produk UMKM ini Dinas Kesehatan juga ikut berperan aktif melakukan pengawasan dan pembinaan terhadap pelaku UMKM dengan turun ke Toko Swalayan dan juga Minimarket untuk memastikan apakah produk UMKM tersebut tersedia di gerai Toko Swalayan dan juga minimarket tersebut. Namun masih belum berjalan sebagaimana mestinya dimana seharusnya adanya kemitraan antara toko swalayan dengan UMKM demi kelancaran usaha masyarakat kecil sehingga tidak tertutup atau tertimpa dengan mini market tersebut, maka pada prinsipnya Pemerintah Kota Pekanbaru melalui Dinas Kesehatan Kota Pekanbaru akan menjembatani UMKM agar dapat bermitra dengan toko swalayan yang ada dengan cara melakukan sosialisai dan himbauan kepada pelaku UMKM agar produk yang mereka masukkan ke toko swalayan dan minimarket sudah ada label PIRT nya. ${ }^{13}$

Berdasarkan hasil wawancara dengan Kepala Bidang Promosi, Pemasaran dan Ekonomi Kreatif Dinas

\footnotetext{
13 Hasil wawancara dengan Bapak Muhammad Amin SIP., M.SI,Kepala Dinas Kesehatan Kota Pekanbaru, hari Rabu, tanggal 3 Juni 2020, di Kantor Dinas Kesehatan Kota Pekanbaru.
} 
Pariwisata Kota Pekanbaru mengenai

Pelaksanaan Peraturan Daerah (Perda)

Nomor 09 Tahun 2014 tentang

Pengelolaan Pasar Rakyat, Pusat

Perbelanjaan dan Toko Swalayan di Kota

Pekanbaru bahwa kita ketahui Pekanbaru

adalah salah satu kota Investasi terbaik

tingkat Nasional. Melalui Dinas

Pariwisata Kota Pekanbaru mengadakan

pembinaan dan pelatihan bekerja sama

dengan instansi terkait saling bersinergi,

dengan cara melakukan event baik

tingkat Kota maupun tingkat Nasional,

kemudian Dinas Pariwisata Kota

Pekanbaru juga memberikan pelatihan

cara paking agar dapat memasarkan

prodak mereka lebih menarik lagi.

Berkaitan dengan produk UMKM Dinas

Pariwisata Kota Pekanbaru menyubutnya

dengan nama Pelaku Ekonomi Kreatif

juga ikut berperan aktif serta ikut dalam

kegiatan event-event yang dilakukan oleh

Dinas Pariwisata Kota Pekanbaru agar produk yang mereka jual lebih dikenal

oleh masyarakat luas dan juga Nasional. ${ }^{14}$

Berdasarkan hasil wawancara

dengan Kepala Kepala Dinas

Perindustrian dan Perdagangan Kota

Pekanbaru mengenai upaya yang

dilakukan dalam mengatasi hambatan

pelaksanaan efektifitas kemitraan antara

UMKM dengan Minimarket berdasarkan

Peraturan Daerah Kota Pekanbaru Nomor

09 Tahun 2014 tentang Pengelolaan Pasar

Rakyat, Pusat Perbelanjaan dan Toko

Swalayan di Kota Pekanbaru bahwa

perlunya upaya sosialisasi yang lebih

14 Berdasarkan hasil wawancara dengan Kepala Bidang Promosi, Pemasaran dan Ekonomi Kreatif Dinas Pariwisata Kota Pekanbaru mengenai Pelaksanaan Peraturan Daerah (Perda) Nomor 09 Tahun 2014 tentang Pengelolaan Pasar Rakyat, Pusat Perbelanjaan dan Toko Swalayan di Kota Pekanbaru bahwa kita ketahui Pekanbaru adalah salah satu kota Investasi terbaik tingkat Nasional. Melalui Dinas Pariwisata Kota Pekanbaru mengadakan pembinaan dan pelatihan bekerja sama dengan instansi terkait saling bersinergi, dengan cara melakukan event baik tingkat Kota maupun tingkat Nasional, kemudian Dinas Pariwisata Kota Pekanbaru juga memberikan pelatihan cara paking agar dapat memasarkan prodak mereka lebih menarik lagi. Berkaitan dengan produk UMKM Dinas Pariwisata Kota Pekanbaru menyubutnya dengan nama Pelaku Ekonomi Kreatif juga ikut berperan aktif serta ikut dalam kegiatan event-event yang dilakukan oleh Dinas Pariwisata Kota Pekanbaru agar produk yang mereka jual lebih dikenal oleh masyarakat luas dan juga Nasional dalam menghasilkan produk yang bersaing. 
terhadap Peraturan Daerah Kota

Pekanbaru Nomor 09 Tahun 2014 tentang

Pengelolaan Pasar Rakyat, Pusat

Perbelanjaan dan Toko Swalayan melalui

Dinas Koperasi dan Pemerintah Kota

Pekanbaru agar setiap Pelaku Usaha Mini

Market dan Toko Swalayan dapat

menjalankan Peraturan yang ada

sebagaimana mestinya demi terciptanya

efektifitas antara Pelaku Usaha Mini

Market dan Toko Swalayan terhadap

UMKM yang ada di Kota Pekanbaru. ${ }^{15}$

Berdasarkan hasil wawancara

dengan Wakil Ketua DPRD Kota

Pekanbaru mengenai upaya yang

dilakukan dalam mengatasi hambatan

pelaksanaan efektifitas kemitraan antara

UMKM dengan Minimarket berdasarkan

Peraturan Daerah Kota Pekanbaru Nomor

09 Tahun 2014 tentang Pengelolaan Pasar

Rakyat, Pusat Perbelanjaan dan Toko

15 Hasil wawancara dengan Bapak Hendra Putra SIP., M.SI, Kepala Bidang Perdagangan Dinas Perindustrian dan Perdagangan Kota Pekanbaru, hari Rabu, tanggal 27 Mei 2020, di Kantor Dinas Perindustrian dan Perdagangan Kota Pekanbaru.
Swalayan di Kota Pekanbaru bahwa perlunya upaya peningkatan dan pembinaan yang lebih lanjut terhadap UMKM, keterbatasan modal kerja maupun investasi; kesulitan-kesulitan dalam pemasaran, distribusi dan pengadaan bahan baku serta input lainnya; keterbatasan akses ke informasi mengenai peluang pasar, masih kurangnya keterbatasan modal usaha serta keterbatasan wawasan (SDM) yang dimiliki sehingga perlunya program dalam bentuk pelatihan seperti rumah kemasan sehingga UMKM memiliki ketrampilan dalam membentuk sebuah kemasan produk yang kreatif dan bagus dengan mensingkronisasi dengan Dinas Perindustrian dan Perdagangan Kota Pekanbaru. ${ }^{16}$

Berdasarkan hasil wawancara dengan beberapa Pelaku usaha

${ }^{16}$ Hasil wawancara dengan Bapak Tengku Azwendi Fajri, SE Wakil Ketua DPRD Kota Pekanbaru, hari Kamis, tanggal 28 Mei 2020, di Kantor DPRD Kota Pekanbaru. 
Minimarket mengenai upaya yang dilakukan dalam mengatasi hambatan

Penerapan Peraturan Daerah Kota

Pekanbaru Nomor 09 Tahun 2014 tentang

Pengelolaan Pasar Rakyat, Pusat

Perbelanjaan dan Toko Swalayan di Kota

Pekanbaru bahwa perlunya peningkatan

produk yang harus dilakukan oleh

UMKM sehingga produk yang pasarkan

tidak terhambat dan konsumen dapat

membeli kebutuhannya sesuai dengan

yang diinginkan dalam rangka menjaga

stabilitas produk dan menjaga konsumen

agar tidak pindah kepada minimarket atau

toko swalan lain. Dan juga perlunya

pembinaan-pembinaan yang dilakukan

oleh Dinas juga agar UMKM dapat

memiliki modal yang dibantu oleh

Pemerintah harapan kedepannya. Serta

perlunya pro aktif dari UMKM dalam

menjaga kualitas produk dan

memperhatikan kembali masa berlakunya

produk tersebut dan memperbagus kembali kemasan sehingga menarik minat para konsumen. ${ }^{17}$

Berdasarkan hasil wawancara dengan beberapa Pelaku Usaha UMKM di Kota Pekanbaru mengenai upaya yang dilakukan dalam mengatasi hambatan pelaksanaan efektifitas kemitraan antara UMKM dengan Minimarket berdasarkan Peraturan Daerah Kota Pekanbaru Nomor 09 Tahun 2014 tentang Pengelolaan Pasar Rakyat, Pusat Perbelanjaan dan Toko Swalayan di Kota Pekanbaru bahwa perlunya upaya pembinaan terhadap UMKM dalam membantu menjalankan usaha masyarakat dengan cara memberikan pelatihan terhadap UMKM yang ada di Kota Pekanbaru serta lebih mensosialisasi Peraturan Daerah Kota Pekanbaru Nomor 09 Tahun 2014 tentang Pengelolaan Pasar Rakyat, Pusat Perbelanjaan dan Toko Swalayan

${ }^{17}$ Hasil wawancara dengan beberapa Pelaku Usaha Mini Market halal Mart, Tull Mart, di Kota Pekanbaru, pada hari Kamis, tanggal 28 Mei 2020, Lokasi di Kota Pekanbaru. 
sehingga seluruh elemen usaha mengetahui aturan yang berlaku demi terciptanya persaingan usaha yang sehat dan tidak saling menjatuhkan satu Pelaku Usaha dengan Pelaku Usaha lainnya. ${ }^{18}$

Prosedural dan Norma yang di terapkan oleh pihak pemerintah dalam hal ini pemerintah Kota Pekanbaru dalam pengembangan UMKM bersifat urgensi dalam pengelolaan pasar dan pengembangan swadaya masyarakat, sehingga masukan dan nasehat dari wawancara dewasa ini dapat terlaksana bagi UMKM di wilayah Kota Pekanbaru.

\section{Penutup}

\section{Kesimpulan}

a. Penerapan Peraturan Daerah Nomor 09 Tahun 2014 tentang Pengelolaan Pasar Rakyat, Pusat Perbelanjaan dan Toko Swalayan di Kota Pekanbaru

\footnotetext{
18 Hasil wawancara dengan beberapa UMKM Bapak/Ibu Siti, Saipul M Ibrahim, Elva Susanti, di Kota Pekanbaru, pada hari Senin, tanggal 18 Mei 2020, lokasi di Kota Pekanbaru.
}

terhadap pelaku usaha Toko Modren dan UMKM belum berjalan dengan baik dan efektif sebagaimana mestinya. Artinya kemitraan antara Toko Swalayan dengan UMKM belum berjalan sesuai dengan Peraturan Daerah Nomor 9 Tahun 2014 tentang Pengelolaan Pasar Rakyat, Pusat Perbelanjaan dan Toko Swalayan dan masih perlu mensosialisasikan Perda kepada para pelaku usaha. Dari peraturan yang telah ada belum ada peraturan pelaksanaan Perda atau Perwako yang memuat bentuk kemitraan secara rinci dan terukur.

b. Hambatan dalam Penerapan Peraturan Daerah Nomor 09 Tahun 2014 tentang Pengelolaan Pasar Rakyat, Pusat Perbelanjaan dan Toko Swalayan di Kota Pekanbaru bahwa kurangnya sarana prasarana dan operasional serta masih rendahnya kesadaran hukum bagi pelaku usaha mini market dan 
toko swalayan ini terhadap Peraturan

Daerah tersebut serta kurangnya kepedualian pelaku usaha terhadap kemitraan dengan pelaku UMKM dan masih kurangnya Sumber Daya Manusia (SDM) serta kurangnya inovasi terhadap prodak yang meraka jual dikarenakan masih adanya UMKM yang belum mengurus perizinan sesuai dengan aturan Peraturan Daerah.

c. Upaya yang dilakukan dalam mengatasi hambatan Penerapan Peraturan Daerah Nomor 09 Tahun 2014 tentang Pengelolaan Pasar Rakyat, Pusat Perbelanjaan dan Toko Swalayan di Kota Pekanbaru bahwa perlunya peningkatan produk atau inovasi yang dilakukan oleh UMKM baik itu tentang kemasan dan juga PIRT ataupun Label Halal sehingga produk yang pasarkan tidak terhambat dan konsumen dapat membeli kebutuhannya sesuai dengan yang diinginkan dalam rangka menjaga stabilitas produk dan menjaga konsumen agar tidak pindah kepada minimarket atau toko swalayan lain.

\section{Saran}

a. Perlu adanya keseriusan dan komitment serta perhatian Pemerintah Daerah terhadap UMKM, berupa pemberian pelatihan, yaitu dengan melatih UMKM, sehingga skill mereka bertambah melalui (baking school, roti, kue, mie basah, jajanan pasar, kue kering, management usaha kecil dan lokakarya), penyedian informasi dan educasi yaitu dengan memanfaatkan media sebagai alat informasi dan edukasi (informasi pasar, prodak, kuis dan kiat/tips), pemberian dukungan keuagan (kredit investasi, kredit modal kerja) melalui bank dan pihak swasta, pemberian motivasi usaha kepada UMKM 
melalui lomba, study banding, plant tour, pameran dan show melalui media tv, untuk merangsang peminat berwiraswasta (enterpreneurship) agar pelaku usaha dapat mengembangkan dan meningkatkan daya saingnya agar bisa bekerja sama dengan toko modern (minimarket) yang ada disekitarnya, serta memberikan manfaat pemberdayaan UMKM, dan juga responsivitas Pemerintah Daerah dalam memberikan alokasi anggaran dan mengaktifkan kegiatan pelatihan yang berkesinambungan bekerja sama dengan pihak swasta serta Perguruan Tinggi memberikan peningkatan pengeahuan dan skill pengusaha UMKM dalam rangka pengingkatan Sumber Daya Manusia (SDM).

b. Hendaknya Pelaku Usaha Toko Swalayan (Minimarket) dan UMKM yang ada di Kota Pekanbaru lebih kompak dan menjalin kemitraan dan juga kepada pelaku usaha Toko Swalayan (Minimarket) memberikan kelonggaran dan kemudahan dalam sistim pembayaran agar pelaku UMKM bisa mandiri dan berkembang untuk meningkatkan perekonomian masyarakat Daerah. Untuk itu dibutuhkan sinergi antara Toko Swalayan (Minimarket) dengan kalangan UMKM sebagai mitra yang saling menguntungkan. Bentuk sinerginya seperti apa bisa melalui pelatihan, memberikan pembinaan dan Toko Swalayan menerima produkproduk dari UMKM.

c. Hendaknya ada suatu wadah organisasi khusus seperti paguyuban dan juga Koperasi yang menaungi UMKM Kota Pekanbaru sebagai pusat informasi untuk mempermudah kinerja Dinas terkait di dalam memberikan 
pengumuman mengenai pelatihan

ataupun ada event-event tertentu guna pengembangan usaha UMKM untuk mempromosikan prodaknya dan juga diharapkan dengan adanaya organisasi yang menaungi UMKM ini nantinya lebih pro aktif dan mapu mengawasi terhadap pihak terkait bila mana tidak menjalankan aturan yang berlaku agar dapat menjembatani kepada pihak yang berwenang, dan diharapkan juga kepada pelaku UMKM dapat memberikan nama produk, PIRT, sertifikat halal, hak paten dan memperbaiki kemasan (berinovasi), melakukan kegiatan melalui program kunjungan, dan arisan antara UMKM. Genjar melakukan promosi, publikasi melalui koran, radio dan juga televise serta media social lainnya.

\section{Daftar Pustaka}

\section{Buku}

Amrizal Harahap, kondisi Pasar Tradisional di Tengah Himpitan Pasar Modren, (Medan: Jasa Press,2010) hlm.21

H. F. Abraham Amos, Sistem Ketatanegaraan Indonesia, (Jakarta: Raja Grafindo Persada, 2005), hlm. 396.

Manalo, H. Selamatkan Pasar Tradisonal, (Jakarta:Gramedia Pustaka Utama, 2011 ), hlm. 13.

Soerjono Soekanto, Teori Sosiologi Tentang Struktur Masyarakat, (Jakarta: Rajawali, 1986), hlm. 37.

Tambunan, T. (2014), UMKM INDONESIA, Usaki, Hal. 359

\section{Jurnal, Skripsi \& Media Masa}

Bastian, A. Fungsi Sosial Pasar Rakyat Bagi Masyarakat Desa Tasik Serai Barat Kecamatan Pinggir Kabupaten Bengkalis, 
Jurnal UNRI: Jom FISIP, Vol. 04, No. 01, 2017, Pp. 01-12.

David A. Masta, Competition and Product Quality In The Supermarket Industry, The Quarterly Journal Of Economics, Volume 126, Issues 3, Agust 2011, Pages 15391591.

Damayanti,, E., (2019) Tinjauan Hukum Islam Terhadap Eksistensi Minimarket Alfamart dan Indomaret di Indonesia, Jurnal Hukum Bisnis Islam, Vol.11, No.02 Pp. 23-25.

Shaleh, A.I., (2021) Efektivitas Formulir A 5 Pada Pemilih Pemula Pemilihan Umum Tahun 2019 di Kota Semarang, Jurnal Meta-Yuridis, Vol. 04., No. 01., P. 06.

www.BPS dalam angka Tahun 2016.com, diakses pada 21 Oktober 2021

www.Dinas Koperasi dan UMKM Kota Pekanbaru.com, diakses 21-Oktober-2021 Azwita, PENERAPAN PERATURAN

DAERAH NOMOR 09 TAHUN 2014
TENTANG PENGELOLAAN PASAR RAKYAT, PUSAT PERBELANJAAN DAN TOKO SWALAYAN DI KOTA PEKANBARU, Universitas Lancang Kuning.

\section{Peraturan Perundang-Undangan}

UUD NRI 1945

Undang-Undang Nomor 5 Tahun 1999 Tentang Larangan Praktik Monopoli dan Persaingan Usaha Tidak Sehat.

Peraturan Daaerah Kota Pekanbaru Nomor

9 Tahun 2014 tentang Pengelolaan Pasar Rakyat, Pusat Perbelanjaan dan Toko Swalayan.

Pasal 1 ayat (18) Peraturan Daerah Kota Pekanbaru Nomor 9 Tahun 2014 tentang Pengelolaan Pasar Rakyat, Pusat Perbelanjaan dan Toko Swalayan. 


\section{Wawancara}

Hasil wawancara dengan Bapak Tengku Azwendi Fajri, SE Wakil Ketua DPRD

Kota Pekanbaru, hari Kamis, tanggal 28

Mei 20020, di Kantor DPRD Kota

Pekanbaru.

Hasil wawancara dengan beberapa Pelaku

Usaha Mini Market halal Mart, Tull Mart,

di Kota Pekanbaru, pada hari Kamis, tanggal 28 Mei 2020, Lokasi di Kota Pekanbaru.

Hasil wawancara dengan beberapa UMKM

Bapak/Ibu Siti, Saipul M Ibrahim,Elva

Susanti, di Kota Pekanbaru, pada hari

Senin, tanggal 18 Mei 2020, lokasi di Kota

Pekanbaru.

Hasil wawancara dengan Bapak Hendra Putra SIP., M.SI, Kepala Bidang Perdagangan Dinas Perindustrian dan Perdagangan Kota Pekanbaru, hari Rabu, tanggal 27 Mei 2020, di Kantor Dinas
Perindustrian dan Perdagangan Kota

Pekanbaru.

Hasil wawancara dengan Bapak Muhammad Amin SIP., M.SI,Kepal Dinas Kesehatan Kota Pekanbaru, hari Rabu, tanggal 3 Juni 2020, di Kantor Dinas Kesehatan Kota Pekanbaru.

Hasil wawancara dengan Ibu Pita Marti, S.H,M.H.,Kepala Bidang Promosi Pemasaran dan Ekonomi Kreatif Dinas Pariwisata Kota Pekanbaru, hari Rabu, tanggal 3 Juni 2020, di Kantor Dinas Pariwisata Kota Pekanbaru.

Hasil wawancara dengan Bapak Tengku Azwendi Fajri, SE Wakil Ketua DPRD Kota Pekanbaru, hari Kamis., tanggal 28 Mei 2020, di Kantor DPRD Kota Pekanbaru.

Hasil wawancara dengan beberapa Pelaku Usaha Mini Market Halal Mart, Tull Mart, di Kota Pekanbaru, pada hari Rabu, 
tanggal 27 Mei 2020, Lokasi di Kota

Pekanbaru.

Hasil wawancara dengan beberapa UMKM

Bapak/Ibu Amy., Aan., Marshal, di Kota

Pekanbaru, pada hari Rabu, tanggal 7 Juni

200., lokasi di Kota Pekanbaru 